УДК [796.8:796.09/378.147:004]

ISSN (Ukrainian ed. Print) 1991-0177 ISSN (Ukrainian ed. Online) 1999-818X 2020, № 6(80), C. $65-72$ doi: $10.15391 /$ snsv.2020-6.010

\title{
Методика оцінки змагальної діяльності одноборців з використанням комп'ютерних технологій
}

\author{
Вячеслав Романенко \\ Валерій Голоха \\ Анатолій Алексєєв \\ Юлія Коваленко
}

Харківська державна академія фізичної культури,

Харків, Україна

Мета: теоретичне обгрунтування, розробка та експериметальна перевірка методики оцінки змагальної діяльності одноборців з використанням комп'ютерних технологій.

Матеріал і методи: теоретичний аналіз та систематизація наукових джерел стосовно стану досліджуваної проблеми, узагальнення сучасного практичного досвіду, інструментальний метод дослідження, метод комп'ютерного програмування, методи математичної статистики. Для здійснення наукового дослідження у даному напрямку на кафедрі одноборств за підтримки фахівців кафедри інформатики та біомеханіки розроблено спеціалізовану комп'ютерну програму, яка дозволяє оптимізувати процес оцінки та аналізу змагальної діяльності одноборців.

Результати: на основі аналізу науково-методичної інформації, джерел інтернету та узагальнення передового практичного досвіду було виявлено, що найбільш дієвим засобом оцінки змагальної діяльностіє відеокомп'ютерний аналіз. Також були визначені основні параметри оцінки змагальної діяльності. Перегляд відеофрагментів бойових ситуацій на змаганнях дозволяє точніше ідентифікувати ту чи іншу дію, умови та оцінку їі виконання. На підставі аналізу даних науково-методичної літератури та узагальнення практичного досвіду стосовно проблематики оцінки та аналізу змагальної діяльності створено комп'ютерну програму «Martial Arts Video Analysis». Використання запропонованої комп'ютерної програми дозволяє оптимізувати процес аналізу змагальної діяльності одноборців. Інформація, яка отримана завдяки цій програмі, дозволить формувати різні моделі змагальної діяльності та розробляти методичні рекомендації щодо підвищення якості тренувального процесу.

Висновки: на підставі аналізу науково-методичної літератури та практичного досвіду визначено найбільш значимі параметри оцінки змагальної діяльності одноборців, розроблено та апробовано методику з використанням комп'ютерних технологій, яка дозволить оптимізувати процес оцінки та аналізу змагальної діяльності одноборців.

Ключові слова: одноборства, змагальна діяльність, відеокомп'ютерний аналіз, методика, параметри, комп'ютерне програмування.

\section{Вступ}

Дослідження різних сторін підготовленості провідних одноборців дозволяє сформувати найбільш затребувані напрямки вдосконалення процесу підготовки спортсменів, які починають брати участь у змаганнях різного рівня $[1,3,4,5]$.

Фахівці, які проводять дослідження в цьому напрямку, вивчають параметри, що відображають, на їх думку, особливості змагальної діяльності одноборців. Так, бразильські дослідники вивчали залежність тривалості атаки, статі та вагової категорії спортсменів [16]. Корейські вчені розглядали аспекти виконання пумсе (формальні вправи) в тхэквондо, які впливають на рішення суддів, а саме переміщення центру мас, висота та кут удару, довжина стійок [18]. Іспанські науковці проаналізували атакуючі дії у залежності від раунду та особливостей поєдинку в тхеквондо [14]. Турецькі дослідники [12], на підставі аналізу 12-го Чемпіонату світу з вільної бороть- би серед університетів, визначили основні показники техніки кваліфікованих борців. Вчені з Польщі [11] досліджували вплив змін у спортивному регламенті тхеквондо на склад технічних дій, які використовують спортсменки. Фахівці з боксу, на підставі аналізу відеозаписей боїв, отримали різноманітні характеристики змагальної боротьби, а саме: коефіцієнти атаки, захисту, коефіцієнти бойових дій [6].

На нашу думку, найбільш дієвим засобом оцінки змагальної діяльності є відеокомп'ютерний аналіз. Перегляд відеофрагментів бойових ситуацій на змаганнях дозволяє точніше ідентифікувати ту чи іншу дію, умови та оцінку їі виконання. Розробка зручної, ефективної методики оцінки та аналізу змагальної діяльності одноборців на сучасному етапі розвитку одноборств та нових можливостей комп'ютерної техніки є актуальним.

Зв'язок роботи з науковими програмами, планами і темами. Дослідження проводилося відповідно до теми науково-дослідної роботи Харківської державної академії фізичної культури: «Психосенсорна регуля-
Романенко, В., Голоха, В., Алексєєв, А., Коваленко, Ю. (2020), «Методика оцінки змагальної діяльності одноборців з використанням комп'ютерних технологій»
Слобожанський науково-спортивний вісник, № 6(80), С. 65-72, doi: $10.15391 /$ snsv.2020-6.010 


\section{СЛОБОЖАНСЬКИЙ НАУКОВО-СПОРТИВНИЙ ВІСНИК}

ція рухової діяльності спортсменів ситуативних видів спорту» (номер державної реєстрації 0116U008943) та теми «Науково-методичні основи використання інформаційних технологій при підготовці фахівців галузі фізичної культури та спорту» (номер державної реєстрації 0113U001207).

Мета дослідження полягає в теоретичному обгрунтуванні, розробці та експериметальній перевірці методики оцінки змагальної діяльності одноборців з використанням комп'ютерних технологій.

\section{Матеріал і методи дослідження}

Для вирішення завдань дослідження використовувалися такі методи: аналіз науково-методичної інформації, джерел інтернету та узагальнення провідного практичного досвіду, інструментальний метод дослідження, метод комп'ютерного програмування, методи математичної статистики.

Для здійснення наукового дослідження у даному напрямку на кафедрі одноборств за підтримки фахівців кафедри інформатики та біомеханіки розроблено спеціалізовану комп'ютерну програму, яка дозволяє оптимізувати процес оцінки та аналізу змагальної діяльності одноборців.

\section{Результати дослідження}

На основі аналізу науково-методичної інформації, джерел інтернету і узагальнення передового практичного досвіду було виявлено, що для оцінки змагальної діяльності використовують різні методики, з яких найбільш затребуваним є відеокомп'ютерний аналіз. Також визначено найбільш значимі параметри оцінки змагальної діяльності, до яких можна віднести: кількість дій, кількість балів, які є оцінкою виконання дії, ефективність виконання дії, різноманітність виконуваних дій та інше.
На підставі висновків, які були зазначині раніше, стосовно проблематики оцінки та аналізу змагальної діяльності створено комп'ютерну програму «Martial Arts Video Analysis».

Алгоритм комп'ютерної програми розроблено таким чином, що дозволяє оперативно фіксувати необхідні моменти змагальної ситуації та оцінювати їх. Головною особливістю роботи програми $є$ те, що параметри оцінки виконуваних дій фахівець створює сам, що дозволяє розширити сферу її використання у різних видах одноборств.

Під час перегляду відеозапису змагання дослідник має можливість зупинитися у необхідний проміжок часу та оцінити дію спортсмена. Комп'ютерна програма здійснює запис часу, назву змагальної дії та бал, на який вона була виконана. Покадровий перегляд відеофрагменту, який передбачено у програмі, дозволяє більш точніше створити хронометраж усіх важливих, на думку дослідника, дій.

Під час створення проєкту змагального поєдинку фахівець має можливість переглянути вже зафіксовані значення та за необхідністю їх змінити. Якщо після збереження проєкту виникла потреба відредагувати його, програма дозволяє змінити дані про спортсменів, змінити оцінки дій, додати або видалити окремі дії.

Після створення проєкту програма дозволяє отримати різноманітні звіти як стосовно окремого двобою, так і серії поєдинків. Також $є$ можливість отримати звіт за поєдинок, який складається з декількох раундів.

У звіті №1 представлені загальні характеристики одного двобою або серії поєдинків: загальна кількість виконаних дій (n), кількість отриманих балів (бал), ефективність усього поєдинку (відношення результативних дій до загальної їх кількості, \%), ефективність у різних частинах поєдинку (\%), середнє значення інтервалів між діями (с), кількість різноманітних дій, які були оцінені балами (n) та їх ефективність ( \%) (рис. 1).

\begin{tabular}{|c|c|c|c|}
\hline 18:52 Чт 8 окт. & & & จ $25 \%$ \\
\hline Parameters & Winner & Loser & \\
\hline 1. Total number of actions ( $n$ ) & 15.4 & 14.8 & \\
\hline 2. Points & 8.3 & 3.3 & \\
\hline 3. Efficiency of fight (\%) & 65.0 & 25.9 & \\
\hline 4. Efficiency 1 part of fight (\%) & 65.2 & 16.7 & \\
\hline 5. Efficiency 2 part of fight (\%) & 54.0 & 27.8 & \\
\hline 6. Efficiency 3 part of fight (\%) & 63.2 & 18.6 & \\
\hline 7. Interval between actions (s) & 9.2 & 8.6 & \\
\hline 8. Standard error of intervals (s) & 3.2 & 2.2 & \\
\hline 9. Diversity of effective actions ( $n$ ) & 3.3 & 1.8 & \\
\hline 10. Efficiency actions (\%) & 68.9 & 54.3 & \\
\hline
\end{tabular}

Рис. 1. Характеристика змагальної діяльності (звіт №1)

Романенко, В., Голоха, В., Алексєєв, А., Коваленко, Ю. (2020), «Методика оцінки змагальної діяльності одноборців з використанням комп'ютерних технологійу
Слобожанський науково-спортивний вісник, № 6(80), С. 65-72, doi:10.15391/snsv.2020-6.010 


\section{СЛОБОЖАНСЬКИЙ НАУКОВО-СПОРТИВНИЙ ВІСНИК}

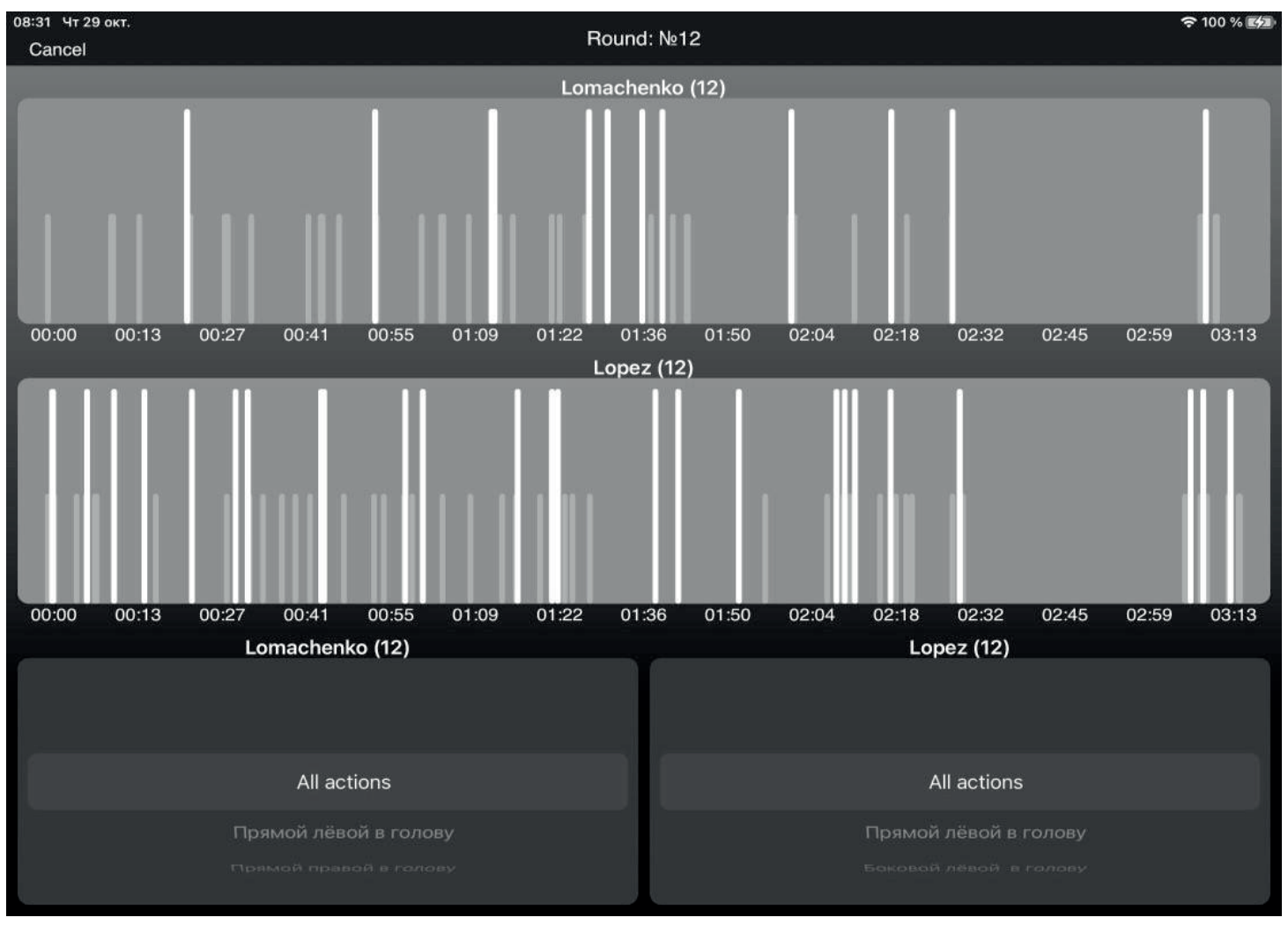

Рис. 2. Хронометраж виконання змагальних дій у поєдинку (звіт №3)

У звіті №2 представлені характеристики двобою або серії поєдинків: список змагальних дій, які були результативними, загальна кількість виконаних дій (у середньому за бій, n), кількість отриманих балів (у середньому за бій, бал), ефективність дій (відношення результативних дій до загальної їх кількості, \%).

Звіт №3 присвячено аналізу змагальних дій у рамках одного двобою, який складається з декілька раундів. У цьому звіті відображено за кожним раундом окремо, загальну кількість змагальних дій, кількість отриманих балів та ефективність виконання цих дій. При виборі раунду дослідник має можливість переглянути хронометраж виконання усіх дій або однієї за вибором (рис. 2).

Комп'ютерна програма «Martial Arts Video Analysis» надає багато можливостей використання проєктів змагальних поєдинків, які було створено, а саме: збереження проєктів у самій програмі або у місці, яке зазначено користувачем, можливість передчі проєктів фахівцям на інші пристрої та їх подальше корегування (при наявності у пристрої відповідного відео).

\section{Висновки / Дискусія}

Дослідження фахівців Ашанін В.С., Романенко В.В. (2015), Podrigalo O., Borisova O., Podrigalo L., lermakov S., Romanenko V., Podavalenko O., Volodchenko O. (2019), Romanenko V., Podrigalo L., Cynarski W., Rovnaya O., Korobeynikova L., Goloha V., Robak I. (2020) підтверджують необхідність та зручність використання комп'ютерних технологій при аналізі різних сторін підготовленості одноборців.

Дослідження Gonzбlez D.E.L. (2013) стверджують, що на підставі відеокомп'ютерного аналізу змагальної діяльності кваліфікованих борців можливо визначити різноманітність дій, ефективність нападу та захисту, коефіцієнти роботи у партері, коефіцієнти тактичної проактивності, середні ефективні дистанції. На основі вивчення цих параметрів дослідник має можливість будувати різні моделі змагальної діяльності одноборців.

Фахівці Остьянов В.Н., Гриб А.І., Копачко О.В. (2010) у такому виді одноборств як бокс стверджують, що підраховуючи кількість ударів, захистів різних видів, а також їх ефективність можна виявити деякі особливості індивідуальної манери ведення двобою. За кількістю таких дій визначають, яка форма бою характерна для того чи іншого спортсмена. Якщо переважають атакуючі удари, то відповідно боксер більше схильний до атакуючої форми.

Аналіз результатів дослідження змагальної діяльності борців греко-римського стилю Тропін Ю.М., Коробейніков Г.В., Шацьких В.В., Коробейнікова Л.Г., Воронцов А.В. (2019) дозволив побудувати модельні характеристики техніко-тактичної підготовленості одноборців у залежності від їх вагових категорій. Моделі, які було представлено фахівцями, можна використовувати при вирішенні питань планування та керування у тренувальному процесі борців.

На думку Романенко В.В., Голохи В.Л., Веретельникова Н.А. (2018), Романенко В.В., Веретельникова Н.А. (2019) використання відеокомп'ютерного аналізу при оцінці змагальної діяльності дозволяє визначати найбільш вагомі напрямки техніко-тактичної підготовки одноборців та розвитку їх функціональних можливостей.

Апробація комп'ютерної програми «Martial Arts Video Analysis» відбувалася фахівцями 3 кафедри одноборств ХДАФК. Було проаналізовано більше 50 двобоїв у таких видах одноборств як таеквон-до, боротьба (греко-римська, 


\section{СЛОБОЖАНСЬКИЙ НАУКОВО-СПОРТИВНИЙ ВІСНИК}

\section{Модельні характеристики змагальних поєдинків кваліфікованих таекводистів}

(модель №1)

\begin{tabular}{|c|l|c|c|c|c|}
\hline $\begin{array}{c}\text { № } \\
\text { ח/ח }\end{array}$ & \multicolumn{1}{|c|}{ Parametrs } & Winner & SEM*(W) & Loser & SEM*(L) \\
\hline 1 & Total number of actions (n) & 17,3 & 3,13 & 15,9 & 2,43 \\
\hline 2 & Points & 10 & 1,49 & 3,3 & 0,9 \\
\hline 3 & Efficiency of the fight (\%) & 37,3 & 6,32 & 16,6 & 5,95 \\
\hline 4 & Efficiency of the first part (\%) & 33,1 & 7,13 & 13,3 & 5,72 \\
\hline 5 & Efficiency of the second part (\%) & 38,5 & 13,19 & 23,5 & 11,9 \\
\hline 6 & Efficiency of the third part (\%) & 32,1 & 8,88 & 15,5 & 8,43 \\
\hline 7 & Interval between actions (s) & 9,5 & 2,06 & 8,9 & 0,63 \\
\hline 8 & Diversity of effective actions (n) & 3,3 & 0,56 & 1,6 & 0,32 \\
\hline 9 & Efficiency actions (\%) & 77,0 & 9,43 & 73,0 & 10,73 \\
\hline
\end{tabular}

* SEM - стандартна помилка середньої арифметичної

вільна), бокс. У якості прикладу, надаємо декілько моделей змагальної діяльності, які були створені у цій програмі.

Перші дві моделі змагальної діяльності (табл. 1, 2) розроблено з перегляду Чемпіонату Світу з таеквон-до 2019 (серія двобоїв n=10, середні вагові категорії).

Згідно з аналізом отриманих результатів спортсмени, які вибороли перемогу, виконують у середньому за поєдинок на 1,4 дії більше, ніж ті, які програли $(17,3 \pm 3,13 ; 15,9 \pm 2,43)$, переможці одержують у середньому на 6,7 балів більше (табл. 1).
Ефективність змагальних дій переможців на

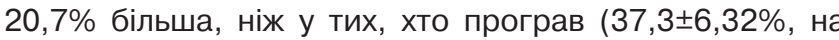
$16,6 \pm 5,95 \%)$. Різноманітність дій, які дозволяють отримати бали, у переможців складає у середньому $3,3 \pm 0,56$

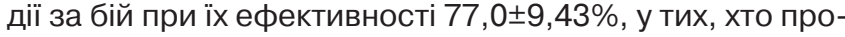

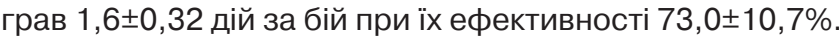
Також слід відзначити великі значення SEM (стандартна помилка середньої арифметичної). Для достовірності висновків щодо аналізу змагальної діяльності одноборців необхідна більша кількість досліджуваних поєдинків.

Таблиця 2

Модельні характеристики змагальних поєдинків кваліфікованих таекводистів (модель №2)

\begin{tabular}{|c|c|c|c|c|}
\hline № & Actions (points \& $\mathrm{n}>0$ & $\begin{array}{l}\text { Total } \\
\text { number }\end{array}$ & $\begin{array}{l}\text { Efficiency of } \\
\text { actions }(\%)\end{array}$ & Points \\
\hline 1 & Dollyo chagi, та, яка ближче до суперника & 1,71 & 16,7 & 0,57 \\
\hline 2 & Dollyo chagi, та, яка подальше від суперника & 1,29 & 33,3 & 0,86 \\
\hline 3 & Dollyo chagi, $з$ обертанням на $360^{\circ}$ & 0,43 & 66,7 & 0,86 \\
\hline 4 & Pandae Dollyo chagi & 0,14 & 100 & 0,43 \\
\hline 5 & Twid chagi & 0,43 & 33,3 & 0,29 \\
\hline 6 & Toro Yop chagi & 0,43 & 100 & 0,86 \\
\hline 7 & Toro Yop chagi у стрибку & 0,43 & 66,7 & 0,57 \\
\hline 8 & Yop chagi у стрибку & 0,14 & 100 & 0,29 \\
\hline 9 & Yop chagi, та, яка ближче до суперника & 4,14 & 13,8 & 1,14 \\
\hline 10 & Yop chagi, та, яка ближче до суперника, на зустрічь & 0,43 & 66,7 & 0,57 \\
\hline 11 & Ap chagi & 0,57 & 25 & 0,29 \\
\hline 12 & Ap joomuk chirugi у стрибку & 0,14 & 100 & 0,29 \\
\hline 13 & Ap joomuk chirugi, та, яка ближче, на зустрічь & 0,57 & 75 & 0,43 \\
\hline 14 & Ap joomuk chirugi, та, яка подальше, на зустрічь & 0,29 & 100 & 0,29 \\
\hline 15 & Ap joomuk chirugi, та, яка ближче & 1,14 & 50 & 0,57 \\
\hline 16 & Ap joomuk chirugi, та, яка подальше & 3,43 & 54,2 & 1,86 \\
\hline
\end{tabular}


Таблиця 3

Модельні характеристики змагальних поєдинків кваліфікованих борців

\begin{tabular}{|c|l|c|c|c|c|}
\hline $\begin{array}{c}\text { № } \\
\text { ח/п }\end{array}$ & \multicolumn{1}{|c|}{ Parametrs } & Winner & SEM*(W) & Loser & SEM*(L) \\
\hline 1 & Total number of actions (n) & 7,9 & 0,53 & 5,8 & 0,59 \\
\hline 2 & Points & 7,6 & 0,48 & 1,4 & 0,36 \\
\hline 3 & Efficiency of the fight (\%) & 53,7 & 3,72 & 11,4 & 2,5 \\
\hline 4 & Efficiency of the first part (\%) & 53,5 & 5,74 & 17,7 & 5,21 \\
\hline 5 & Efficiency of the second part (\%) & 37,6 & 6,97 & 2,2 & 1,52 \\
\hline 6 & Efficiency of the third part (\%) & 34,3 & 5,96 & 6,9 & 2,65 \\
\hline 7 & Interval between actions (s) & 40,6 & 4,36 & 49,4 & 6 \\
\hline 8 & Diversity of effective actions (n) & 2,6 & 0,17 & 0,8 & 0,17 \\
\hline 9 & Efficiency actions (\%) & 92,4 & 2,51 & 40,8 & 8,35 \\
\hline
\end{tabular}

* SEM - стандартна помилка середньої арифметичної

Також є цікавим визначити які ж беспосередньо змагальні дій забеспечують перемогу (табл. 2).

Так, згідно з аналізом результатів (табл. 2), частіше всього переможці виконуть «Үор chagi» - удар ногою, тією, яка ближче до суперника $(n=4,14)$, ефективність удару дорівнює $13,8 \%$ і отримують за його виконання 1,14 бала та «Ap joomuk chirugi» - удар рукою, тією, яка подалі від суперника $(n=3,43)$, ефективність удару дорівнює 54,2\% і отримують за його виконання 1,86 бала. Деякі удари стосовно цієї серії поєдинків (Pandae Dollyo chagi, Toro Yop chagi, Yop chagi у стрибку, Ap joomuk chirugi, на зустріч) мають високу ефективність (100\%), це пов'язано з тим, що ці дії достатньо складні у технічному виконанні і використовуються рідко, але ймовірність отримання переможних балів є високою.

Другу модель розроблено на підставі перегляду Чемпіонату України з вільної боротьби 2020 р. (серія двобоїв n=30, середні вісові категорії) (табл. 3).

Згідно з аналізом отриманих результатів спортсмени, які вибороли перемогу, виконують у середньому за поєдинок на 2,1 прийомів більше, ніж ті, які програли ( $n=7,9 ; n=5,8)$, та отримують 7,6 $\pm 0,48$ перможних балів

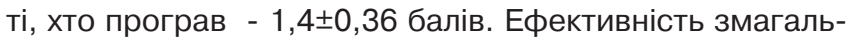
них дій переможців вища, ніж у тих, хто програв (за поєдинок: $53,7 \pm 3,72 \%$, на $11,4 \pm 2,5 \%$ ). Також, відзначено, що в усіх частинах поєдинку переможці мають більш ефективну техніку (1 частина двобою - 53,5 $\pm 5,74 \%$ на

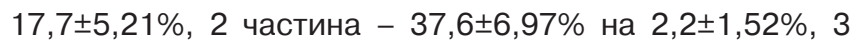

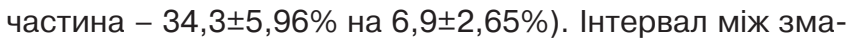
гальними діями у переможців склав 40,6士4,36 с, у тих, хто програв на 8,8 с більше $(49,4 \pm 6,0$ с). Різноманітність дій, які дозволяють отримати бали, у переможців складає у середньому 2,6 0,17 дії за бій при їх ефективності 92,4\%, у тих хто програв - 0,8ะ0,17 дії за бій при їх ефективності 40,8 $8,35 \%$ (табл. 3 ).

Комп'ютерна програма «Martial Arts Video Analysis» дозволяє будувати різні моделі змагальної діяльності. Маючі у базі даних достатню кількість поєдинків та використовуючи функцію вибору, можливо здійснювати аналіз стосовно вагових категорій, віку, рангу змагань, окремо оцінювати жіночі двобої та інше.

На підставі аналізу науково-методичної літератури та практичного досвіду визначено найбільш значимі параметри оцінки змагальної діяльності одноборців, а саме: кількість дій, оцінка та ефективність їх виконання, різноманітність, інтервал між діями та інше.

Розроблено та апробовано методику з використанням комп'ютерних технологій, яка дозволить оптимізувати процес оцінки та аналізу змагальної діяльності одноборців.

Перспективи подальших досліджень будуть спрямовані на розширення можливостей комп'ютерної програми «Martial Arts Video Analysis» $з$ точки зору аналізу змагальної діяльності, підвищення продуктивності та стабільності її роботи.

Конфлікт інтересів. Автори заявляють, що відсутній конфлікт інтересів, який може сприйматись таким, що може завдати шкоди неупередженості статті.

Джерела фінансування. Ця стаття не отримала фінансової підтримки від державної, громадської або комерційної організації.

Романенко, В., Голоха, В., Алексєєв, А., Коваленко, Ю. (2020), «Методика оцінки змагальної діяльності одноборців з використанням комп'ютерних технологій» 


\section{Список посилань}

1. Арансон М. В., Шустин Б. Н. (2018), «Актуальные направления анализа соревновательной деятельности единоборцев», Педагогические науки, Выпуск №9(75), С 99-101.

2. Ашанин В. С., Романенко В. В. (2015), «Использование компьютерных технологий для оценки сенсомоторных реакций в единоборствах», Слобожанський науково-спортивний вісник, № 4, С. 15-18.

3. Козіна Ж. Л., Демура І. М. (2010), «Результати застосування методів математичного моделювання для визначення індивідуальних тактичних манер ведення сутички у дзюдоїстів високого класу», Теорія та методика фізичного виховання, № 7 , С. 17-38.

4. Коробейніков Г. В., Аксютін В. В., Смоляр І. І. (2015), «Зв'язок стилів ведення поєдинку боксерів із психо-фізіологічними характеристиками», Педагогіка, психологія та медико-біологічні проблеми фізичного виховання і спорту, №9, С. 33-37.

5. Коробейніков Г. В., Тропін Ю. М., Вольський Д. С., Жирнов О. В., Коробейникова Л. Г., Чернозуб А. А. (2020), «Розробка алгоритму оцінки нейродинамічних властивостей спортсменів-кікбоксерів», Єдиноборства, №3, С. 36-48.

6. Остьянов В. Н., Гриб А. И., Копачко О. В. (2010), «Змагальна діяльність боксерів важких і легких вагових категорій», Педагогіка, психологія та медико-біологічні науки, №4, С. 94-98.

7. Романенко В.В. (2008), «Биомеханический анализ основных приёмов выполняемых ногами», Физическое воспитание студентов творческих специальностей, №3, С. 44-49.

8. Романенко В. В., Веретельникова Н. А. (2019), «Оценка биомеханических характеристик в ударных видах единоборств с помощью мобильного приложения», Единоборства, №1, С. 48-57.

9. Тропин Ю. М., Коробейников Г. В., Шацких В. В., Коробейникова Л. Г., Воронцов А. В. (2019), «Модельные характеристики технико-тактической подготовленности борцов высокой квалификации греко-римского стиля различных весовых категорий», Наука в олимпийском спорте, №1, С. 29-35.

10. Gonzбlez D.E.L. (2013), «Wrestler's Performance Analysis through Notational Techniques», International Journal of Wrestling Science, Vol.3, Issue2, pp. 68-89.

11. Iermakov S., Podrigalo L., Romanenko V., Tropin Y., Boychenko N., Rovnaya O. (2016), «Psycho-physiological features of sportsmen in impact and throwing martial arts», Journal of Physical Education and Sport, Vol. 16(2), pp. 433-441.

12. Imamoglu O., Erkin A., Mayda M. H. et al. (2017), «12 th Universities Wrestling Championship Free Style Competition Technica Analysis», European Journal of Physical Education and Sport Science. Volume 3, Issue 11, pp. 182 - 193

13. Kruszewski A., Kuźmicki S., Podchul A., Kruszewski M. (2014), «Effect of change sinthe sports regulations on the fight of taekwondo female players on the example of Beijing Olympic Tournaments 2008 and London 2012», Journal of Combat Sports and Martial Arts, Vol. 5, 2(2), pp. 97-100.

14. Menescardi C., Lopez-Lopez J.A., Falco C. et al. (2015), «Tactical aspect so fanational university taekwondo championship in relation to round and match out come», J Strength Cond Res 29(2), pp. 466-471.

15. Romanenko V., Podrigalo L., Cynarski W., Rovnaya O., Korobeynikova L., Goloha V., Robak I. (2020), «A comparative analysis of the short-term memory of martial arts' athletes of different level of sportsmanship», Journal of Martial Arts Anthropology, №20(3), pp. 18-24.

16. Santos V.G.F., F.de Oliveira Pires, Bertuzzi R. et al. (2014), «Relationship between attack and pause in world taekwondo championship contests: effects of gender and weight category», Muscles, Ligaments and Tendons Journal, 4 (2), pp. $127-131$.

17. Podrigalo O., Borisova O., Podrigalo L., lermakov S., Romanenko V., Podavalenko O., Volodchenko O. (2019), «Comparative analysis of the athletes' functional condition in cyclic and situational sports», Physical education of students №23(6), pp. 313-319.

18. Jo Y. M., Kim Y. S., Hong S. H. et al. (2018), «Kinematic Analysis of Taekwondo Koryo Poomsae for Accurate Scoring in Competition», Journal of the International Association for Taekwondo Research, No. 3(2), pp.17-25.

Стаття надійшла до редакції: 07.12.2020 р.

Опубліковано: 21.12.2020 p.

Аннотация. Вячеслав Романенко, Валерий Голоха, Анатолий Алексеев, Юлия Коваленко. Методика оценки соревновательной деятельности единоборцев с использованием компьютерных технологий. Цель: теоретическое обоснование, разработка и экспериментальная проверка методики оценки соревновательной деятельности единоборцев с использованием компьютерных технологий. Материал и методы: теоретический анализ и систематизация научных источников относительно состояния разработки исследуемой проблемы, обобщение современного практического опыта, инструментальный метод исследования, метод компьютерного программирования, методы математической статистики. Для реализации научного исследования в данном направлении на кафедре единоборств при поддержке специалистов кафедры информатики и биомеханики разработана специализированная компьютерная программа, которая позволяет оптимизировать процесс оценки и анализа соревновательной деятельности единоборцев. Результаты: на основании анализа научно-методической информации, источников интернета и обобщения передового практического опыта было выявлено, что наиболее действенным средством оценки соревновательной деятельности является видеокомпьютерный анализ. Также были определены основные параметры оценки соревновательной деятельности. Просмотр видеофрагмента боевых ситуаций на соревнованиях позволяет точнее идентифицировать то или иное действие, условия и оценку его исполнения. На основании анализа данных научно-методической литературы и обобщения практического опыта касательно проблематики оценки и анализа соревновательной деятельности разработана компьютерная программа «Martial Arts Video Analysis». Использование предложенной компьютерной программы позволяет оптимизировать процесс анализа соревновательной деятельности единоборцев. Информация, которая получена благодаря этой программе, позволит создавать разные модели соревновательной деятельности и разрабатывать методические рекомендации для повышения качества тренировочного процесса. Выводы: на основании анализа научно-методической литературы и практического опыта определены наиболее значемые параметры оценки соревновательной деятельности единоборцев, разработана и апробирована методика с использованием компьютерных технологий, которая позволит оптимизировать процесс оценки и анализа соревновательной деятельности единоборцев.

ключевые слова: единоборства, соревновательная деятельность, видеокомпьютерный анализ, методика, параметры, компьютерное программирование.

Романенко, В., Голоха, В., Алексєєв, А., Коваленко, Ю. (2020), «Методика оцінки змагальної діяльності одноборців з використанням комп'ютерних технологій» 
Abstract. Vyacheslav Romanenko, Valeriy Goloha, Anatoly Aleksieiev, Julia Kovalenko. Methods of evaluation of competitive activity of wrestlers with the use of computer technologies. Purpose: to theoretically substantiate, develop and experimentally test evaluation methods of competitive activity of combat athletes using computer technologies. Material and methods: theoretical analysis and systematization of scientific sources on the state of the research problem, generalization of modern practical experience, instrumental research method, computer programming method, methods of mathematical statistics. To carry out a research in this area Department of Martial Arts with the support of specialists of the Department of Informatics and Biomechanics developed a specialized computer program that allows to optimize the process of evaluation and analysis of competitive activity of wrestlers. Results: based on the analysis of scientific and methodological information, Internet sources and generalization of best practices, it was found that the most effective means of assessing competitive activity is video computer analysis. Also, the main parameters of competitive activity evaluation were determined. Viewing video clips of combat situations at competitions allows to identify a particular action, conditions and evaluation of its implementation more accurately. On the basis of data analysis of scientific and methodical literature and generalization of practical experience, concerning problems of an estimation and the analysis of competitive activity, the computer program "Martial Arts Video Analysis" is created. The use of the proposed computer program allows to optimize the process of analysis of competitive activities of wrestlers. The information obtained through this program will allow to form various models of competitive activity and develop guidelines for improving the quality of the training process. Conclusions: based on the analysis of scientific and methodological literature, practical experience the most significant parameters for evaluating the competitive activity of wrestlers were identified, methods with the use of computer technology that will optimize the process of evaluation and analysis of competitive activities of wrestlers was developed and tested.

Keywords: martial arts, competitive activity, video computer analysis, methods, parameters, computer programming.

\section{References}

1. Aranson, M. V., Shustin, B. N. (2018), «Actual directions of the analysis of the competitive activity of combatants», Pedagogicheskie nauki, Vypusk 9(75), pp. 99-101 (in Russ).

2. Ashanin, V. S., Romanenko, V. V. (2015), «The use of computer technologies to assess sensorimotor reactions in single combats», Slobozhans'kij naukovo-sportivnij visnik, No. 4, pp. 15-18 (in Russ).

3. Kozina, Zh. L., Demura, I. M. (2010), «The results of the application of mathematical modeling methods to determine the individual tactical manners of the fight in high-class judokas», Teorija ta metodika fizichnogo vihovannja, No. 7, pp. 17-38. (in Ukr.).

4. Korobejnikov, G. V., Aksjutin, V. V., Smoljar, I. I. (2015), «The relationship between boxing styles and psycho-physiological characteristics", Pedagogika, psihologija ta mediko-biologichni problemi fizichnogo vihovannja i sportu, No. 9, pp. 33-37 (in Ukr.).

5. Korobejnikov, G. V., Tropin, Ju. M., Vol's'kij, D. S., Zhirnov, O. V., Korobejnikova, L. G., Chernozub, A. A. (2020), «Development of an algorithm for assessing the neurodynamic properties of kickboxing athletes», Єdinoborstva, No. 3, pp. $36-48$ (in Ukr.).

6. Ost'janov, V. N., Grib, A. I., Kopachko, O. V. (2010), «Competitive activity of boxers of heavy and light weight categories», Pedagogika, psihologija ta mediko-biologichni nauki, pp. 94-98 (in Ukr.).

7. Romanenko, V. V. (2008), «Biomechanical analysis of basic techniques performed by the legs», Fizicheskoe vospitanie studentov tvorcheskih special'nostej, No. 3, pp. 44-49 (in Russ).

8. Romanenko, V. V., Veretel'nikova, N. A. (2019), «Assessment of biomechanical characteristics in percussion martial arts using a mobile application», Edinoborstva, No. 1, pp. 48-57 (in Russ).

9. Tropin, Ju. M., Korobejnikov, G. V., Shackih V. V., Korobejnikova, L. G., Voroncov, A. V. (2019), «Model characteristics of technical and tactical readiness of highly qualified wrestlers in Greco-Roman style of various weight categories", Nauka v olimpijskom sporte, No. 1, pp. 29-35 (in Russ).

10. Gonzбlez, D.E.L. (2013), «Wrestler's Performance Analysis through Notational Techniques», International Journal of Wrestling Science, Vol.3, Issue2, pp. 68-89 (in Eng.).

11. lermakov, S., Podrigalo, L., Romanenko, V., Tropin, Y., Boychenko, N., Rovnaya, O. (2016), «Psycho-physiological features of sportsmen in impact and throwing martial arts», Journal of Physical Education and Sport, Vol. 16(2), pp. $433-441$ (in Eng.).

12. Imamoglu, O., Erkin, A., Mayda, M.H. et al. (2017), «12 th Universities Wrestling Championship Free Style Competition Technical Analysis», European Journal of Physical Education and Sport Science. Volume 3, Issue 11, pp. 182 - 193 (in Eng.).

13. Kruszewski, A., Kuźmicki, S., Podchul, A., Kruszewski, M. (2014), «Effect of change sinthe sports regulations on the fight of taekwondo female players on the example of Beijing Olympic Tournaments 2008 and London 2012", Journal of Combat Sports and Martial Arts, Vol. 5, 2(2), pp. 97-100 (in Eng.).

14. Menescardi, C., Lopez-Lopez, J.A., Falco, C. et al. (2015), «Tactical aspect so fanational university taekwondo championship in relation to round and match out come», J Strength Cond Res 29(2), pp. 466-471 (in Eng.).

15. Romanenko, V., Podrigalo, L., Cynarski, W., Rovnaya, O., Korobeynikova, L., Goloha, V., Robak, I. (2020), «A comparative analysis of the short-term memory of martial arts' athletes of different level of sportsmanship", Journal of Martial Arts Anthropology, No. 20(3), pp. 18-24 (in Eng.).

16. Santos, V.G.F., F.de Oliveira Pires, Bertuzzi, R. et al. (2014), «Relationship between attack and pause in world taekwondo championship contests: effects of gender and weight category», Muscles, Ligaments and Tendons Journal, 4 (2), pp. 127-131 (in Eng.).

17. Podrigalo, O., Borisova, O., Podrigalo, L., lermakov S., Romanenko, V., Podavalenko, O., Volodchenko, O. (2019), «Comparative analysis of the athletes' functional condition in cyclic and situational sports», Physical education of students No. 23(6), pp. 313-319 (in Eng.).

18. Jo, Y.M., Kim, Y.S., Hong, S.H. et al. (2018), «Kinematic Analysis of Taekwondo Koryo Poomsae for Accurate Scoring in Competition», Journal of the International Association for Taekwondo Research, No. 3(2), pp. 17-25 (in Eng.).

Received: 07.12.2020.

Published: 21.12.2020.

Романенко, В., Голоха, В., Алексєєв, А., Коваленко, Ю. (2020), «Методика оцінки змагальної діяльності одноборців з використанням комп'ютерних технологій, 


\section{СЛОБОЖАНСЬКИЙ НАУКОВО-СПОРТИВНИЙ ВІСНИК}

\section{Відомості про авторів / Information about the Authors}

Романенко Вячеслав Валерійович: к.фіз.вих., доцент; Харківська державна академія фізичної культури: вул. Клочківська, 99, м. Харків, 61058, Україна.

Романенко Вячеслав Валерьевич: к.физ.восп., доцент; Харьковская государственная академия физической культуры: ул. Клочковская, 99, г. Харьков, 61058, Украина.

Vyacheslav Romanenko: PhD (Physical Education and Sport), Associate Professor; Kharkiv State Academy of Physical Culture: Klochkivska st., 99, Kharkov, 61058, Ukraine.

ORCID.ORG /0000-0002-3878-0861

E-mail: slavaromash@gmail.com

Голоха Валерій Леонідович: Харківська державна академія фізичної культури: вул. Клочківська, 99, м. Харків, 61058 Україна.

Голоха Валерий Леонидович: Харьковская государственная академия физической культуры: ул. Клочковская, 99, г. Харьков, 61058, Украина.

Valeriy Goloha: Kharkiv State Academy of Physical Culture: Klochkivska st., 99, Kharkov, 61058, Ukraine.

ORCID.ORG /0000-0003-3733-5560

E-mail: vgolokha@gmail.com

Алексєєв Анатолій Федотович: професор; Харківська державна академія фізичної культури: вул. Клочківська, 99, м. Харків, 61058, Україна.

Алексеев Анатолий Федотович: профессор; Харьковская государственная академия физической культуры: ул. Клочковская 99, г. Харьков, 61058, Украина.

Anatoly Aleksieiev: professor; Kharkiv State Academy of Physical Culture: Klochkivska st., 99, Kharkov, 61058, Ukraine.

ORCID.ORG /0000-0002-9311-2858

E-mail: af.aleks38@gmail.com

Коваленко Юлія Миколаївна: Харківська державна академія фізичної культури: вул. Клочківська, 99, м. Харків, 61058 Україна.

Коваленко Юлия Николаевна: Харьковская государственная академия физической культуры; ул. Клочковская 99 г. Харьков, 61058, Украина.

Julia Kovalenko: Kharkiv State Academy of Physical Culture: 99 Klochkivska St., Kharkiv, 61058, Ukraine.

ORCID.ORG /0000-0002-5736-4249

E-mail: julawa09@gmail.com 